\title{
Coalescence of functional gold and monodisperse silver nanoparticles mediated by black Panax ginseng Meyer root extract
}

This article was published in the following Dove Press journal:

International Journal of Nanomedicine

8 December 2016

Number of times this article has been viewed

\author{
Dandan Wang' \\ Josua Markus² \\ Yeon-Ju Kim' \\ Chao Wang' \\ Zuly Elizabeth Jiménez \\ Pérez ${ }^{2}$ \\ Sungeun Ahn' \\ Verónica Castro Aceituno' \\ Ramya Mathiyalagan ${ }^{2}$ \\ Deok Chun Yang ${ }^{1,2}$ \\ 'Department of Oriental Medicine \\ Biotechnology and Ginseng Bank, \\ ${ }^{2}$ Department of Biotechnology \\ and Ginseng Bank, College of Life \\ Sciences, Kyung Hee University, \\ Yongin, Republic of Korea
}

Correspondence: Deok Chun Yang; Yeon-Ju Kim

Department of Oriental Medicine Biotechnology and Ginseng Bank, College of Life Sciences, Kyung Hee University, 1732, Deogyeong-daero, Giheung-gu, Yongin-si, Gyeonggi-do 17104,

Republic of Korea

$\mathrm{Tel}+82312012100$

Fax +82312052688

Email dcyang@khu.ac.kr;

yeonjukim@khu.ac.kr
Abstract: A rapid biological synthesis of multifunctional gold nanoparticle (AuNp) and monodisperse silver nanoparticle ( $\mathrm{AgNp}$ ) was achieved by an aqueous extract of black Panax ginseng Meyer root. The physicochemical transformation into black ginseng (BG) greatly enhanced the pharmacological activities of white ginseng and its minor ginsenoside content. The optimal temperature conditions and kinetics of bioreduction were investigated. Formation of BG-AuNps and BG-AgNps was verified by ultraviolet-visible spectrophotometry at 548 and $412 \mathrm{~nm}$, respectively. The biosynthesized BG-AgNps were spherical and monodisperse with narrow distribution, while BG-AuNps were icosahedral-shaped and moderately polydisperse. Synthesized nanoparticles exhibited long-term stability in buffers of $\mathrm{pH} \mathrm{7.0-8.0} \mathrm{and} \mathrm{bio-}$ logical media ( $5 \%$ bovine serum albumin) at an ambient temperature and at $37^{\circ} \mathrm{C}$. BG-AgNps showed effective antibacterial activity against Escherichia coli and Staphylococcus aureus. BG-AuNps and BG-AgNps demonstrated increased scavenging activity against 2,2-diphenyl1-picrylhydrazyl free radicals. In addition, BG-AuNps and BG-AgNps were nontoxic to HaCaT and MCF-7 cells; the latter showed no cytotoxicity at concentrations lower than $10 \mu \mathrm{g} / \mathrm{mL}$. At higher concentrations, BG-AgNps exhibited apparent apoptotic activity in MCF-7 breast cancer cell line through reactive oxygen species generation and nuclear fragmentation.

Keywords: gold nanoparticles, silver nanoparticles, monodispersity, spectroscopy, cytotoxicity, antioxidant activity, anticancer activity

\section{Introduction}

Monodisperse nanoparticles have emerged as an important research target due to their superior biomedical, electronic, optical, and magnetic applications than polydisperse nanoparticles. ${ }^{1}$ Moreover, their uniform nano-sized dimensions have been favorable in medical diagnostics, ${ }^{2}$ pharmacy, ${ }^{3}$ preparation of cosmetics ${ }^{4}$ and catalysts, ${ }^{5}$ and water treatment. ${ }^{6}$ An important and challenging task in the current situation is to develop a one-step, rapid, economical, and eco-friendly methodology which evades the use of hazardous chemicals and excessive energy consumption. ${ }^{7,8}$ Thus, green methodologies can be helpful to the development of metallic nanoparticles, especially for the benefit of human health. ${ }^{9}$ In this study, an unprecedented rapid synthesis of functional gold nanoparticles (AuNps) and monodisperse silver nanoparticles (AgNps) is reported using an aqueous extract of black Panax ginseng Meyer root by green chemistry.

$P$. ginseng Meyer is a famous traditional medicinal plant widely used in China, Republic of Korea, Japan, and other Asian countries. ${ }^{10}$ Its major principal and bioactive components are ginsenosides; in recent decades, more than 180 ginsenosides have been isolated and reported in various pharmacological and pharmaceutical studies. ${ }^{11,12}$ 
Ginsenosides and ginseng extract have been reported to possess antiaging, anticancer, antistress, antidiabetic, antioxidant, and anti-inflammatory effects. ${ }^{13-15}$ The nine-time repetitive steaming process that transforms white ginseng (WG) into red ginseng (RG) and black ginseng (BG) significantly increases the pharmacological activities of bioactive components. ${ }^{16}$ It was reported that ginsenosides 20(S)-Rg3, 20(R)-Rg3, Rk1, and Rg5 exist in RG and BG but not in WG. Specifically, these specific ginsenosides which exist in $\mathrm{RG}$ as minor ginsenosides are much increased in $\mathrm{BG}$ (Figure S1) with increasing pharmacological activity against human cancer cells. ${ }^{17}$ In addition, the acidic polysaccharide contents of ginseng extracts are present in the following order: $\mathrm{BG}>\mathrm{RG}>\mathrm{WG}$. Furthermore, the reducing sugars and phenolic contents in BG are much higher than WG and RG. ${ }^{16}$ In light of these enhanced physicochemical properties and ginsenoside contents of BG, the biosynthesis route utilizing black $P$. ginseng Meyer root extract is propitious for the development of multifunctional nanoparticles with in vitro biological applications.

AuNps have emerged as promising agents for cancer diagnosis and therapy. They also have demonstrated excellent biomedical applications as mediators in drug delivery and biomedical imaging. ${ }^{2,18}$ Ultrafine AuNps have been reported as safe for use in drug delivery system in a recent in vivo study by Naz et al. ${ }^{19}$ They concluded that long-term exposure to AuNps did not cause noticeable deterioration in mice and complete elimination through urinary excretion was observed. Furthermore, AgNps have been explored rigorously as antibacterial agents in textiles, wound dressings, and medical devices. ${ }^{20-25}$ Likewise, they have received notoriety due to their enhanced antimicrobial, anticoagulant, biofilm-inhibiting, anticancer, and anti-inflammatory efficacies, which make them ideal candidates on biomedical platform. ${ }^{26}$

This is the first study to report the biosynthesis of functional BG-AuNps and monodisperse BG-AgNps using black $P$. ginseng Meyer root extract which has important in vitro biological applications. Biosynthesized nanoparticles were thoroughly characterized and evaluated for their scavenging activities against 2,2-diphenyl-1-picrylhydrazyl (DPPH) free radicals. In addition, BG-AgNps were tested for their antimicrobial activity against Escherichia coli and Staphylococcus aureus. Lastly, in vitro cytotoxicity of the biosynthesized nanoparticles was studied in human keratinocyte (HaCaT) and human breast adenocarcinoma (MCF-7) cell lines.

\section{Materials and methods Materials}

Korean WG (P. ginseng Meyer) was obtained from Ginseng Genetic Resource Bank (Suwon, Republic of Korea). Silver nitrate $\left(\mathrm{AgNO}_{3}\right)$, gold (III) chloride trihydrate $\left(\mathrm{HAuCl}_{4} \cdot 3 \mathrm{H}_{2} \mathrm{O}\right), \mathrm{DPPH}$, and gallic acid were purchased from Sigma-Aldrich Chemicals (St Louis, MO, USA). Bacterial growth media (Difco ${ }^{\mathrm{TM}}$ ) were purchased from MB Cell (Seoul, Republic of Korea). The pathogenic bacterial strains E. coli (ATCC 10798) and S. aureus (ATCC 6538) were used. Antibiotic discs were obtained from Oxoid Ltd. (England). The bacterial strains were cultured on nutrient agar media at $37^{\circ} \mathrm{C}$ for 24 hours and preserved at $70^{\circ} \mathrm{C}$ in glycerol stock vials for further study.

\section{Preparation of aqueous extract of black $P$. ginseng Meyer root}

Black $P$. ginseng Meyer root was obtained after nine-time repetitive steaming of $\mathrm{WG}$ at $100^{\circ} \mathrm{C}$ for 3 hours and drying at $60^{\circ} \mathrm{C}$ for 24 hours. ${ }^{27} \mathrm{BG}$ root powder was obtained by pulverizing $\mathrm{BG}$ root. To obtain $\mathrm{BG}$ root extract, $5 \mathrm{~g}$ of BG root powder was boiled for 30 minutes with $100 \mathrm{~mL}$ of sterile distilled water. After 30 minutes of boiling, the BG root extract was recovered by filtering the solution using Whatman filter paper. The collected extract was centrifuged at 10,000 rpm for 10 minutes, and the supernatant was obtained. The total volume of filtrate was maintained at $100 \mathrm{~mL}$ and stored at $4^{\circ} \mathrm{C}$ for further use (Scheme 1). ${ }^{28-30}$

\section{Green synthesis of AuNps and AgNps}

Five milliliters from the $100 \mathrm{~mL}$ BG stock filtrate was mixed with $25 \mathrm{~mL}$ of sterile distilled water. The precursor gold and silver salts were added into their respective mixtures to reach a final concentration of $1 \mathrm{mM}$. The effect of temperature was studied by performing the bioreduction at different reaction temperatures. Kinetics of the bioreduction was studied by recording ultraviolet-visible (UV-Vis) absorbance at the optimal temperature as a function of time. The change in the color of the reaction mixtures indicated the formation of $\mathrm{BG}-\mathrm{AuNps}$ and $\mathrm{BG}-\mathrm{AgNps}$ in the respective reaction mixtures. After the color change was observed, biosynthesized nanoparticles were purified and collected: the reaction mixture was first centrifuged at 2,000 rpm for 10 minutes to remove any other undesirable components. Then, the mixture was continuously washed with sterile distilled water and centrifuged at 16,000 rpm for 15 minutes to obtain the nanoparticles in pellet form. Finally, the purified nanoparticles 


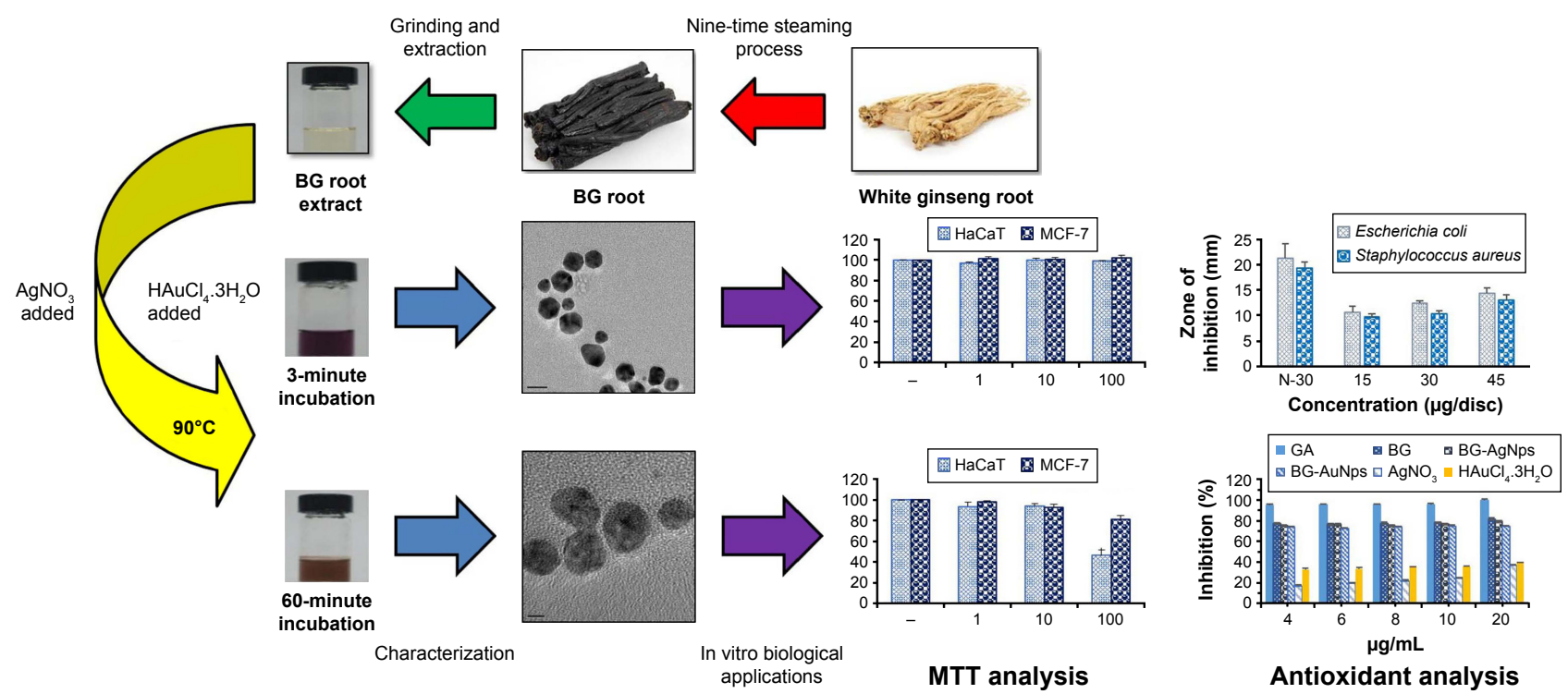

Scheme I Preparation and characterization of black ginseng root extract.

Abbreviations: BG, black ginseng; MTT, 3-(4,5-dimethyl-2-thiazolyl)-2,5-diphenyl-2H tetrazolium bromide; GA, gallic acid; AgNps, silver nanoparticles; AuNps, gold nanoparticles.

were air dried overnight and obtained in powder form. The products were further characterized by UV-Vis spectrophotometry, field emission transmission electron microscopy (FE-TEM), energy-dispersive X-ray spectrometry (EDX), $\mathrm{X}$-ray diffraction (XRD), selected area electron diffraction, elemental mapping, particle size analyzer, and Fourier transform-infrared (FTIR) spectrometry.

\section{Characterization of BG-AuNps and BG-AgNps}

UV-Vis spectroscopy was used to verify the reduction of metal ions into metallic nanoparticles. Small aliquots of the respective solution $(200 \mu \mathrm{L})$ were scanned in the range of 300-800 nm using a UV-Vis spectrophotometer with a $10 \mathrm{~mm}$ pathlength quartz cuvette (2100 Pro; Amersham Biosciences Corp., Little Chalfont, UK).

The size, shape, and purity of the nanoparticles were analyzed using a JEM-2100F electron microscope operated at a voltage of $200 \mathrm{kV}$ (JEOL, Tokyo, Japan). Droplets of purified nanoparticles were placed on carbon-coated copper grids and allowed to dry in an oven at $60^{\circ} \mathrm{C}$.

The XRD analyses were performed on an X-ray diffractometer (D8 Advance; Bruker, Billerica, MA, USA) operated at $40 \mathrm{kV}$ and $40 \mathrm{~mA}$, with $\mathrm{CuK} \alpha$ radiation of $1.54 \AA$, at a scanning rate of $6^{\circ}$ minute and a step size of $0.02^{\circ}$. Samples were scanned over the $2 \theta$ range of $20^{\circ}-80^{\circ}$. The average crystal size diameter of metal nanoparticles was calculated by Debye-Scherrer equation: $D=0.9 \lambda / \beta \cos \theta$, where $D$ is the crystallite size $(\mathrm{nm}), \lambda$ is the wavelength of $\mathrm{CuK} \alpha$ radiation $(\mathrm{nm}), \beta$ is the full width at half maximum (FWHM) (radians), and $\theta$ is half of the Bragg angle (radians). ${ }^{31}$

A particle size analyzer was used to examine the distribution profile of nanoparticles using dynamic light scattering (DLS; DLS-Photal; Otsuka Electronics, Tokyo, Japan) technique. The hydrodynamic ( $Z$-average) diameter and polydispersity index (PDI) were evaluated at $25^{\circ} \mathrm{C}$. A dispersive medium of pure water with a refractive index of 1.3328 , viscosity of 0.8878 , and dielectric constant of 78.3 was used as a reference.

To examine the nature of biomolecules responsible for providing protective capping layer around the nanoparticles, FTIR measurements were performed on a PerkinElmer Spectrum One FTIR spectrometer in the range of $4,000-450 \mathrm{~cm}^{-1}$ and at a resolution of $4 \mathrm{~cm}^{-1}$.

To study the stability of the biosynthesized nanoparticles, reaction mixtures were stored for different time intervals at room temperature and $37^{\circ} \mathrm{C}$ in distilled water, $20 \mathrm{mM}$ glycine- $\mathrm{HCl}$ buffer ( $\mathrm{pH} 2.0$ ), citric acid-sodium citrate buffer (pH 5.0), sodium phosphate buffer ( $\mathrm{pH}$ 7.0), Tris-HCl buffer (pH 8.0), and 5\% bovine serum albumin (BSA). ${ }^{32}$ Stability of the nanoparticles was confirmed if there was no significant alteration in the absorbance and surface plasmon wavelength observed by a UV-Vis spectrophotometer.

\section{Antimicrobial activity of BG-AgNps}

The antimicrobial activity of BG-AgNps was evaluated against pathogenic microorganisms E. coli (ATCC 10798) 
and S. aureus (ATCC 6538). Zones of inhibition were measured on Muller-Hinton agar (MHA) plates using the discdiffusion method. In this assay, the MHA agar plates were spread evenly with $100 \mu \mathrm{L}$ of an overnight log culture of each pathogenic microorganism in lysogeny broth media with an optical density of 0.1 . Standard antibiotic disc of neomycin (30 $\mu \mathrm{g} / \mathrm{disc})$ was maintained as control and placed onto inoculated MHA agar plates. Next, on separate MHA agar plates previously streaked by pathogens, different concentrations of the purified BG-AgNps solution (15,30, and $45 \mu \mathrm{g} / \mathrm{disc})$ were added onto sterile paper discs. The plates were incubated at $37^{\circ} \mathrm{C}$ for 24 hours. Finally, the zones of inhibition around sterile discs impregnated with BG-AgNps were measured and compared against antibiotic discs. All experiments were performed in triplicates to check reproducibility, and their means \pm standard errors were calculated. ${ }^{19,26}$

\section{In vitro DPPH radical-scavenging assay}

Free radical-scavenging activity of BG-AuNps and BGAgNps was evaluated by a modified DPPH-scavenging method. ${ }^{33}$ To $0.3 \mathrm{~mL}$ of purified nanoparticle solution was added $2.7 \mathrm{~mL}$ of $0.1 \mathrm{mM}$ DPPH solution in $80 \%$ methanol. ${ }^{34}$ Different concentrations of metal nanoparticle solutions $(4,6$, 8,10 , and $20 \mu \mathrm{g} / \mathrm{mL}$ ) were utilized to determine $\mathrm{IC}_{50}$ by linear regression analysis. Each mixture was sonicated in the dark at room temperature for 30 minutes. Supernatants were collected by centrifugation, and absorbance was measured at $517 \mathrm{~nm}$ using a UV-Vis spectrophotometer. ${ }^{33}$ The DPPH free radical-scavenging activity was evaluated using the following formula: ([Absorbance of control - Absorbance of sample]/ Absorbance of control) $\times 100$, where Absorbance of sample is the absorbance of the DPPH solution with nanoparticles and Absorbance of control is the absorbance of the DPPH solution without nanoparticles. ${ }^{35}$ Gallic acid was used as positive control. All experiments were performed in triplicates to check reproducibility, and their means \pm standard errors were calculated.

\section{In vitro MTT cell proliferation assay}

$\mathrm{HaCaT}$ and $\mathrm{MCF}-7$ cell lines were purchased from the American Type Culture Collection (ATCC) (Manassas, VA, USA). Both cell lines were cultured in Dulbecco's Modified Eagle's Medium (DMEM) (Gibco-BRL, Grand Island, NY, USA) supplemented with 10\% fetal bovine serum and $1 \%$ penicillin/streptomycin (WelGENE Inc., Daegu, Republic of Korea) at $37^{\circ} \mathrm{C}$ in a humidified atmosphere containing $5 \%$ $\mathrm{CO}_{2}$ and $95 \%$ air. $^{36}$ The cytotoxicity of BG-AuNps and BGAgNps in $\mathrm{HaCaT}$ and MCF-7 cell lines was examined using
3-(4,5-dimethyl-2-thiazolyl)-2,5-diphenyl-2H-tetrazolium bromide (MTT) (Life Technologies, Eugene, OR, USA) assay. Both cell lines were maintained in DMEM and seeded at a density of $1 \times 10^{4}$ cells per well in a 96-well plate (Corning Incorporated, Corning, NY, USA) and then treated with different concentrations of BG-AuNps and BG-AgNps $(0,1$, 10 , and $100 \mu \mathrm{g} / \mathrm{mL}$ ) at $37^{\circ} \mathrm{C}$ for 72 hours at $90 \%$ confluency. After 3 days of incubation, $10 \mu \mathrm{L}$ of MTT assay solution ( $5 \mathrm{mg} / \mathrm{mL}$ phosphate-buffered saline [PBS]) was added to each well and further incubated at $37^{\circ} \mathrm{C}$ for 4 hours. Then, $100 \mu \mathrm{L}$ of dimethyl sulfoxide was added to dissolve the formazan crystals. Finally, the absorbance of each well was measured at $570 \mathrm{~nm}$ using an enzyme-linked immunosorbent assay reader (Bio-Tek Instruments, Inc., Winooski, VT, USA). The optical density of formazan formed in untreated cells (negative control) represented 100\% cell viability. All experiments were performed in triplicates to check reproducibility, and their means \pm standard errors were calculated. ${ }^{36}$

\section{Reactive oxygen species (ROS) generation and Hoechst nuclear staining}

The generation of ROS was determined by $2^{\prime}, 7^{\prime}$ dichlorofluorescein diacetate (DCFH-DA) reagent as described previously. ${ }^{36}$ Briefly, MCF-7 cells were plated in a 12 -well plate. After 24 hours of incubation, the cells were treated with different concentrations of BG-AuNps and BGAgNps for 48 hours. The cells were washed with PBS and incubated with $10 \mu \mathrm{M} \mathrm{DCFH}-\mathrm{DA}$ at $37^{\circ} \mathrm{C}$ for 30 minutes. The DCF fluorescence was measured using fluorescence multiwell plate reader at excitation and emission wavelengths of 485 and $528 \mathrm{~nm}$.

MCF-7 nucleus staining was done by the following or previous procedure ${ }^{37}$ In brief, cells were plated in six-well plates and incubated for 24 hours. Nanoparticles were added to each well according to the experimental groups, and incubated for 72 hours. The cells were washed twice with $1 \times$ PBS and fixed with $3.7 \%(\mathrm{v} / \mathrm{v})$ formaldehyde for 5 minutes at room temperature. Prior to staining, the cells were washed twice with $1 \times$ PBS and stained with $2 \mu \mathrm{g} / \mathrm{mL}$ Hoechst for 30 minutes in dark conditions at room temperature. Images of the Hoechst fluorescence were captured using a fluorescence microscope ( $\times 400$; Optinity; Korean Labtech) for further analysis.

\section{Results and discussion Effect of temperature and kinetics of BG-AuNps and BG-AgNps synthesis}

In this study, a green and rapid synthesis of multifunctional BG-AuNps and monodisperse BG-AgNps was achieved 
extracellularly using an aqueous extract of black $P$. ginseng Meyer root. To the authors' knowledge, this is the first report on the biosynthesis of BG-AuNps and BG-AgNps using BG root extract without the addition of hazardous solvents and capping agents. The extract of BG root contains many phytochemicals, some of which are more abundant than those found in RG and WG as previously explained. These phytochemicals, including ginsenosides, play an important role in the synthesis of BG-AuNps and BG-AgNps. A previous in situ study by Leonard et al demonstrated the synthesis of stable and monodisperse AuNps using RG root powder. They suggested that phytochemicals within $P$. ginseng Meyer plant functioned as excellent reducing and stabilizing agents which prevented AuNps from further aggregation. ${ }^{32}$

The formation of BG-AuNps and BG-AgNps was observed by a UV-Vis spectrophotometer at different reaction temperatures and times. Figure $1 \mathrm{~A}$ and $\mathrm{B}$ shows that at room temperatures $\left(23^{\circ} \mathrm{C}\right)$, surface plasmon wavelengths $\left(\lambda_{\max }\right)$ of BG-AuNps and BG-AgNps could be detected. This shows that the formation of BG-AuNps and BG-AgNps could be achieved at an ambient temperature, albeit with a slow reduction rate. When temperature was raised to $90^{\circ} \mathrm{C}$ in both instances, major absorption peaks at 548 and $412 \mathrm{~nm}$ of BG-AuNps and BG-AgNps, respectively, became much more pronounced. As shown by the results, the optimal temperature for the synthesis of nanoparticles was $90^{\circ} \mathrm{C}$ (Figure 1A and B). Previous studies have established that an increase in reaction temperature leads to a decrease in nanoparticle size, whereas a decrease in reaction temperature results in an increase in particle size. ${ }^{38,39}$ However, at a temperature higher than $80^{\circ} \mathrm{C}-90^{\circ} \mathrm{C}$, although the reaction kinetically becomes more agreeable, nanoparticle aggregation tends to become more prominent. ${ }^{40}$

The reduction of silver nitrate and gold (III) chloride trihydrate was evident from the color change of the reaction mixture observed visually after the incubation period at $90^{\circ} \mathrm{C}$. In case of BG-AgNps, the reaction mixture completely turned to brown within a hour, and no further color change was observed after 4.5 hours of incubation (Figure 1D). Similarly for BG-AuNps, the reaction mixture completely turned to purple after 3 minutes of incubation period at $90^{\circ} \mathrm{C}$ and was completed in 25 minutes (Figure 1C). A negative control (BG root extract) without precursor salts was prepared alongside the reaction mixtures, and no color change was observed. This indicated that color changes were prompted by the reduction of metal ions into their respective nanoparticles. The intense color change to deep brown and purple observed in the reaction mixtures was the response of surface plasmon resonance due to the oscillation of free electrons of the conduction band of BG-AuNps and BG-AgNps, respectively. ${ }^{41,42}$ Furthermore, the activation energy, $E_{\mathrm{a}}$, and rate constants, $k$, were calculated from Arrhenius equation. The values of rate constants at different temperatures are shown in Table 1. As the reaction temperature increased to $90^{\circ} \mathrm{C}$, the reduction became kinetically more favorable (ie, higher rate constant). The values of activation energy
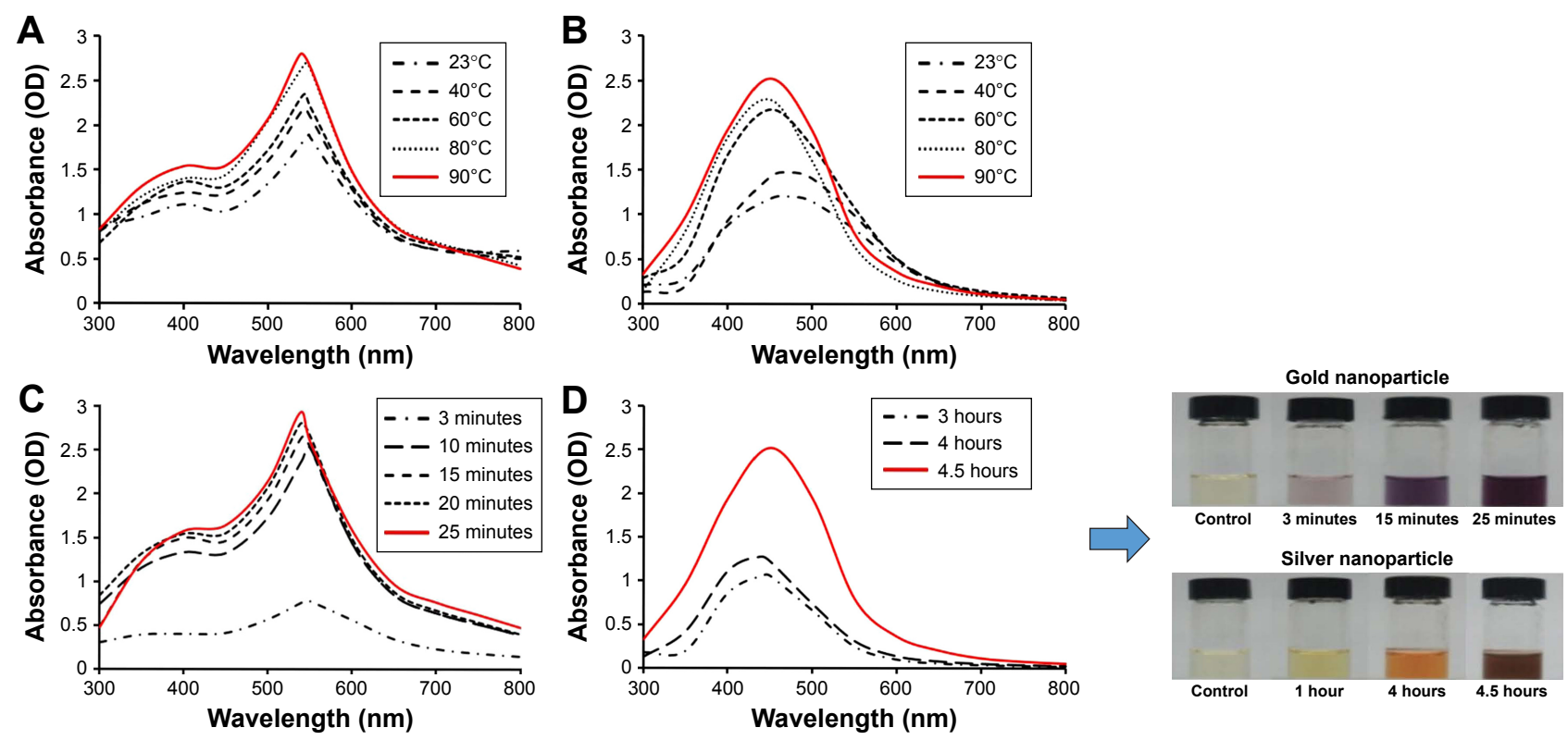

Figure I Temperature-dependent UV-Vis spectra of the reaction mixture for BG-AuNps (A) and BG-AgNps (B). Time-dependent UV-Vis spectra of the reaction mixture for BG-AuNps (C) and BG-AgNps (D).

Abbreviations: UV-Vis, ultraviolet-visible; BG, black ginseng; AuNps, gold nanoparticles; AgNps, silver nanoparticles; OD, optical density. 
Table I Rate constants at different temperatures

\begin{tabular}{|c|c|c|c|c|c|c|}
\hline \multirow[t]{2}{*}{ Temperature } & \multicolumn{2}{|l|}{$60^{\circ} \mathrm{C}$} & \multicolumn{2}{|l|}{$80^{\circ} \mathrm{C}$} & \multicolumn{2}{|l|}{$90^{\circ} \mathrm{C}$} \\
\hline & AgNps & AuNps & AgNps & AuNps & AgNps & AuNps \\
\hline$k\left(\min ^{-1}\right)$ & $1.10 \times 10^{-3}$ & $5.57 \times 10^{-2}$ & $1.9 \times 10^{-3}$ & $1.45 \times 10^{-1}$ & $2.30 \times 10^{-3}$ & $1.81 \times 10^{-3}$ \\
\hline
\end{tabular}

Abbreviations: $k$, rate constant; AgNps, silver nanoparticles; AuNps, gold nanoparticles.

of gold and silver bioreduction were estimated to be 40.69 and $25.06 \mathrm{~kJ} / \mathrm{moL}$, respectively. The bioreduction of gold had a higher $E_{\mathrm{a}}$ value than silver, and thus, the reaction was more sensitive to temperature change than the bioreduction of silver ions.

\section{Structural and morphological characterization of BG-AuNps and BG-AgNps}

The FE-TEM results revealed that the BG-AuNps and BGAgNps were icosahedral and spherical (Figure 2A and E). EDX analysis was conducted to analyze the purity of the purified BG-AuNps and BG-AgNps. Maximum EDX peaks were determined at 2.3 and $3 \mathrm{keV}$, which were the characteristic peaks of metallic gold and silver, respectively (Figure 2D and $\mathrm{H}$ ). Moreover, the elemental mapping results showed the distribution profile of BG-AuNps and BG-AgNps in their respective FE-TEM image (Figure $2 \mathrm{~B}$ and $\mathrm{F}$ ). Elemental mapping revealed that gold (red) and silver (green) were the prevailing elements in the corresponding nanoparticles, further validating the purity of the biosynthesized nanoparticles (Figure 2C and G).

The metallic crystal structure of the biologically synthesized BG-AuNps and BG-AgNps was analyzed by XRD. The experiment was performed by scattering a beam of $\mathrm{X}$-rays to diffract through atoms of nanoparticle crystals. The characteristic peaks of biosynthesized BG-AuNps and BGAgNps were computed in the spectrum of $2 \theta$ value ranging
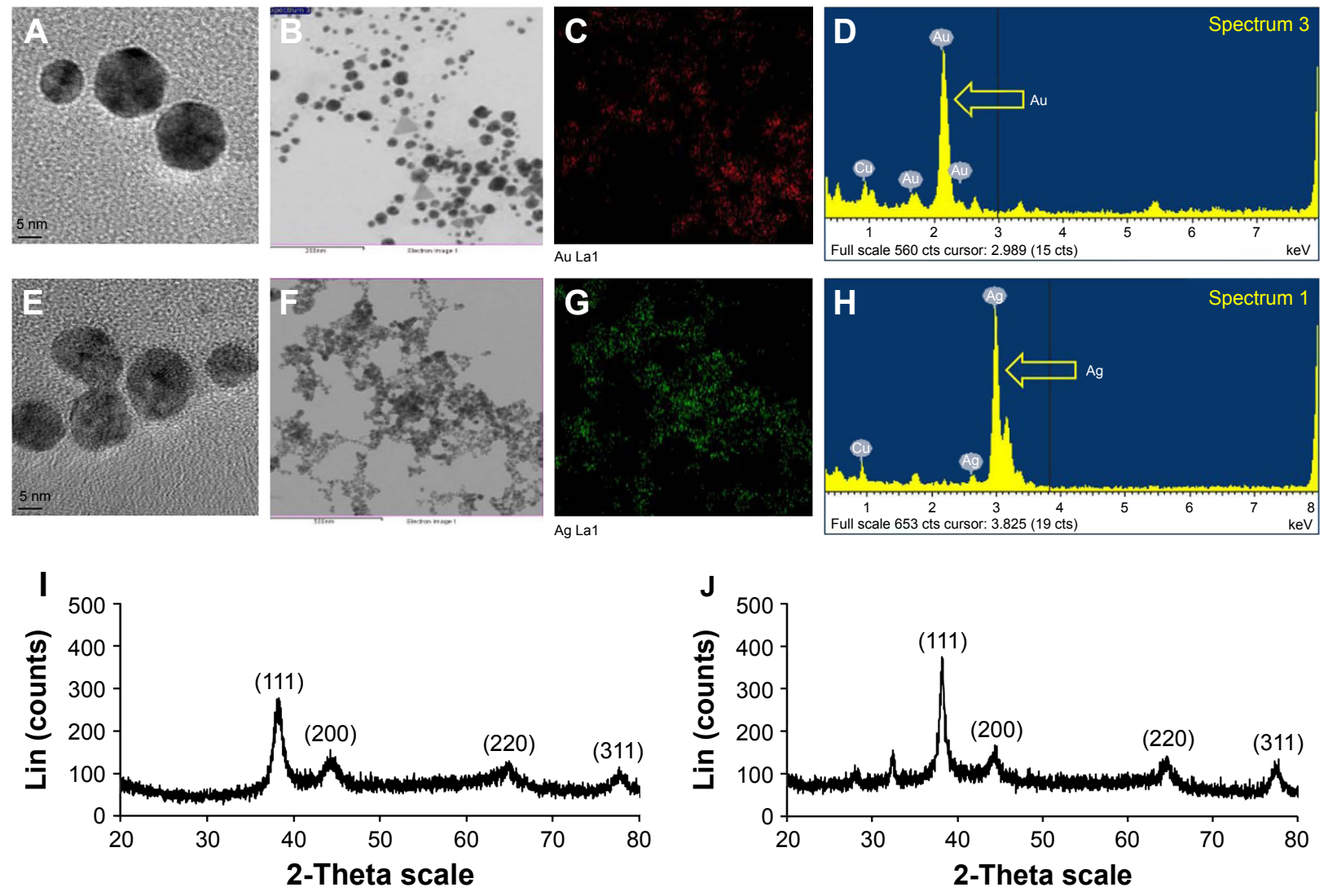

Figure 2 FE-TEM images of icosahedral BG-AuNps (A) and spherical BG-AgNps (E). Elemental mapping results indicate the distribution of element gold (B) and silver (F) nanoparticle pellet solution; gold (red) (C) and silver (green) (G). EDX spectra of BG-AuNps (D) and BG-AgNps (H). XRD results indicate the crystallinity of biosynthesized nanoparticles of BG-AuNps (I) and BG-AgNps (J).

Abbreviations: FE-TEM, field emission transmission electron microscopy; BG, black ginseng; AuNps, gold nanoparticles; AgNps, silver nanoparticles; EDX, energy-dispersive X-ray spectrometry; XRD, X-ray diffraction. 
from $20^{\circ}$ to $80^{\circ}$. Four peaks were obtained from each sample (Figure 2I-J). The characteristic peaks of gold (measured at $38.33^{\circ}, 44.31^{\circ}, 64.90^{\circ}$, and $77.69^{\circ}$ ) and silver (measured at $38.22^{\circ}, 44.24^{\circ}, 64.26^{\circ}$, and $77.69^{\circ}$ ) were indexed to diffraction peaks of (111), (200), (220), and (311) lattice plane of Bragg's reflection. The intensities measured at (111) lattice planes were much higher in the XRD spectra, which suggested that the metal nanoparticles were face-centered cubic and (111) oriented. The average diameter of metal nanoparticles was estimated by Debye-Scherrer equation. ${ }^{31}$ The biogenic BG-AuNps and BG-AgNps were found to have an average crystallite size of 5 and $8 \mathrm{~nm}$, respectively. The hydrodynamic size distributions of BG-AuNps and BG-AgNps were detected using DLS analysis. The DLS analysis results showed the distribution of nanoparticles with respect to number, volume, and intensity (Figure 3). The results showed that the $Z$-average size of BG-AgNps was $213.20 \mathrm{~nm}$ with a PDI value of 0.10 , which indicates that the biosynthesized BG-AgNps were monodisperse with a narrow distribution. ${ }^{26}$ The $Z$-average size of BG-AuNps was $273.40 \mathrm{~nm}$ with a PDI value of 0.13 , which suggested that the biosynthesized BG-AuNps were moderately polydisperse in nature.

FTIR spectra of silver salt (curve a), gold salt (curve b), BG-AgNps (curve c) and BG-AuNps (curve d) are demonstrated in Figure 4 and were compared against BG root extract (curve e) which acted as the positive control. The FTIR spectrum of the BG root extract showed strong peaks at $3,428,1,630$, and $1,027 \mathrm{~cm}^{-1}$ which corresponded to $\mathrm{O}-\mathrm{H}$ stretching vibration of hydroxyl groups in polyphenylene flavonoids, $\mathrm{C}=\mathrm{O}$ stretching vibration of tertiary amine linkages due to amino acid or protein residues, and $\mathrm{C}-\mathrm{O}$ stretching of flavonoid esters, respectively. ${ }^{43,44}$ Additionally, shared medium peak at $2,927 \mathrm{~cm}^{-1}$ indicated the vibration of C-H stretching of methyl groups. ${ }^{45}$ The FTIR spectra of BG-AuNps and BG-AgNps showed similar peaks as BG root extract spectrum, albeit with different intensities. BG-AgNps exhibited weaker bands $\left(3,422,2,917,1,635\right.$, and $\left.1,025 \mathrm{~cm}^{-1}\right)$ than the biomolecules surrounding BG-AuNps $(3,421,2,918$, 1,637 , and $1,021 \mathrm{~cm}^{-1}$ ). This was further supported by the
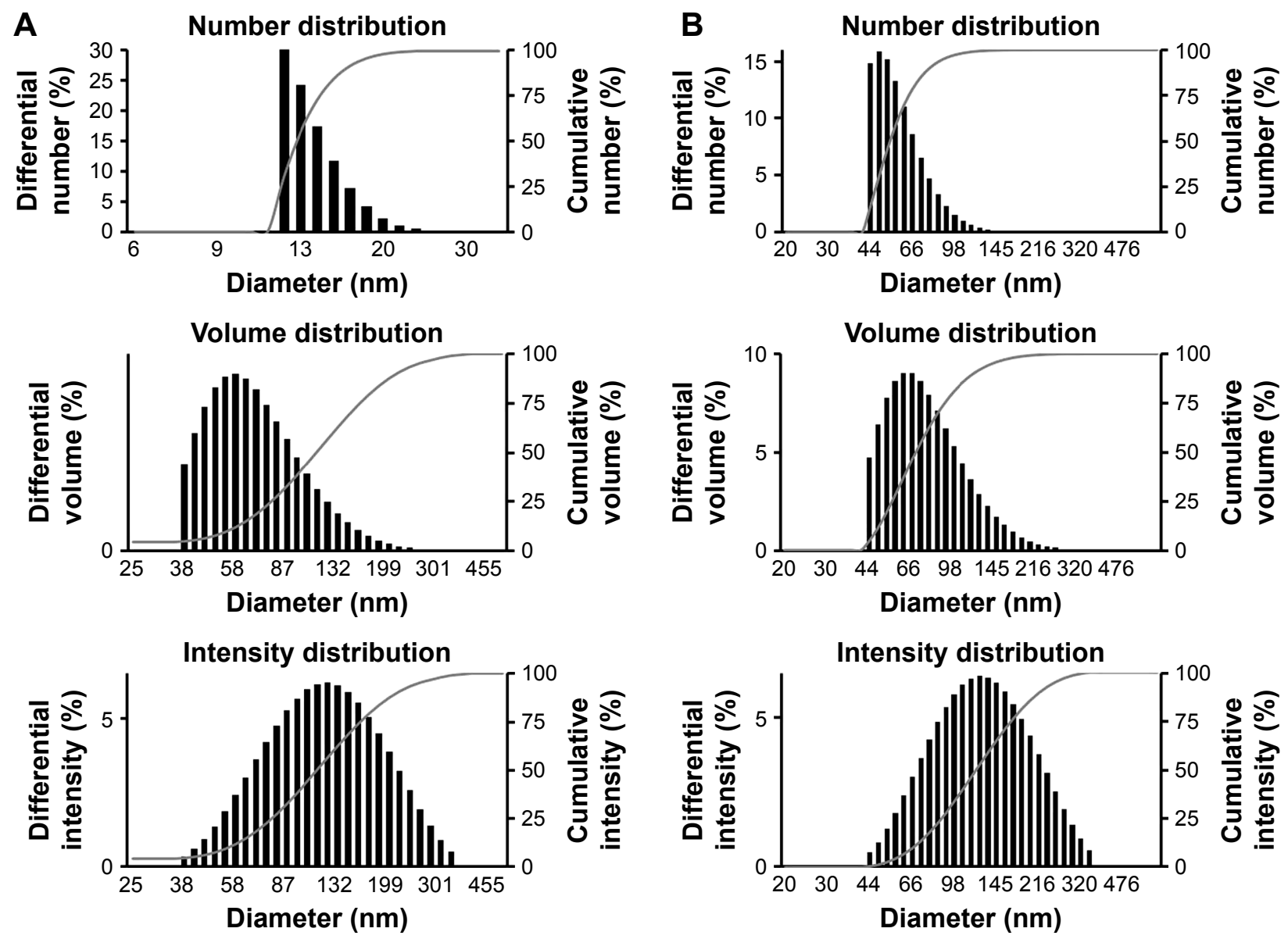

Figure 3 Particle size distribution of BG-AuNps (A) and BG-AgNps (B) with respect to number, volume, and intensity. Abbreviations: BG, black ginseng; AuNps, gold nanoparticles; AgNps, silver nanoparticles. 


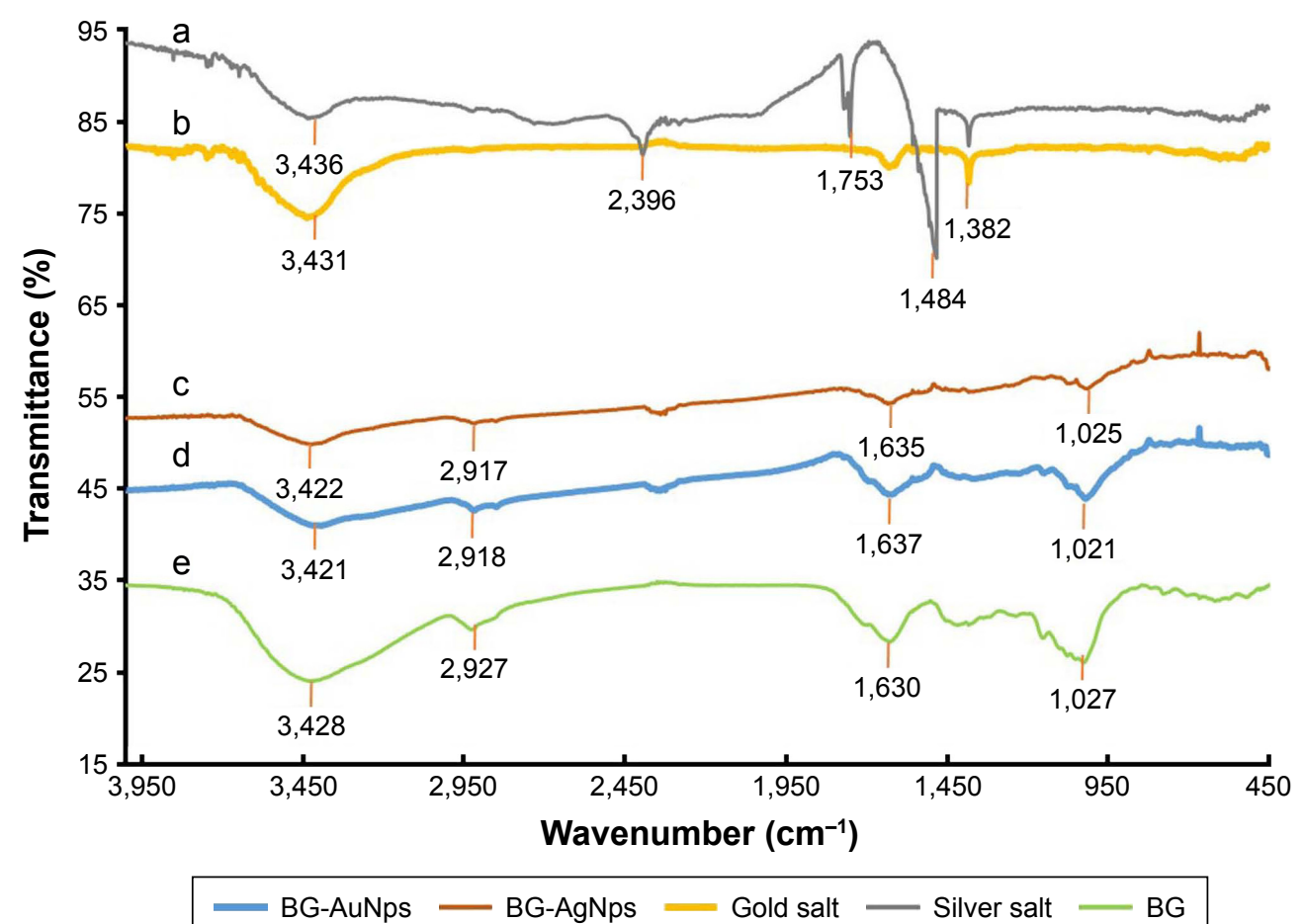

Figure 4 FTIR absorption spectra of silver salt (a), gold salt (b), BG-AgNps (c), BG-AuNps (d), and BG root powder (e).

Abbreviations: FTIR, Fourier transform-infrared; BG, black ginseng; AgNps, silver nanoparticles; AuNps, gold nanoparticles.

smaller hydrodynamic diameter (ie, smaller protective capping layer) of BG-AgNps compared to BG-AuNps. Thus, polyphenylene flavonoid, proteins, and flavonoid esters in the BG root extract may have been responsible for the reduction and capping of biosynthesized BG-AuNps and BG-AgNps. ${ }^{46}$

The stability of the nanoparticles was evaluated by analyzing their UV-Vis absorbance spectrum before and after the incubation in different $\mathrm{pH}$ conditions $(\mathrm{pH} 2.0-8.0)$ at $37^{\circ} \mathrm{C}$. Overall, there was no apparent difference in absorbance and surface plasmon wavelength $\left(\lambda_{\max }\right)$ in reaction mixtures with distilled water, sodium phosphate buffer ( $\mathrm{pH} 7.0)$, Tris- $\mathrm{HCl}$ buffer ( $\mathrm{pH} 8.0)$, and 5\% BSA solution at room temperature and $37^{\circ} \mathrm{C}$ after 7 days. These results confirmed the colloidal stability of BG-capped gold and AgNps in pH 7.0-8.0 and biological media (5\% BSA).

\section{Antibacterial activity of BG-AgNps against $E$. coli and S. aureus}

Various studies have shown the antibacterial activity of AgNps against pathogenic microorganisms. ${ }^{47,48}$ In this study, antibacterial activity of BG-AgNps was evaluated using standard zone-of-inhibition microbiology assay, as compared to standard antibiotics (Figure 5A and B). Figure 5A and $\mathrm{B}$ shows the dose-dependent antimicrobial activity of
BG-AgNps tested against pathogenic E. coli and $S$. aureus at three $(15,30$, and $45 \mu \mathrm{g})$ different concentrations. Based on the zones of inhibition summarized in Figure 5C, biosynthesized BG-AgNps demonstrated effective zones of inhibition against $E$. coli and moderate inhibition against S. aureus. BG-AgNps given at $30 \mu \mathrm{g} /$ disc were debilitated by aggregation, and thus were not able to demonstrate larger zones of inhibition. The mechanism of antimicrobial activity of BG-AgNps has yet to be elucidated. However, it is suggested that the positively charged silver ions accumulated around the nanoparticles damage cell membranes, which ultimately leads to loss of permeability and cell death. ${ }^{26}$ The zone of inhibition may be caused due to the large surface area of AgNps which provides better surface contact to microorganisms. An increase of silver ions accumulating at the bacterial membrane may result in a concentration gradient and transmembrane movement of positive silver ions into the interior of cells, which ultimately leads to structural changes in the cell membrane, thereby causing loss of permeability and cell death. ${ }^{26,49,50}$

\section{Antioxidant activity of BG-AuNps and BG-AgNps}

In vitro DPPH assay of nanoparticles is determined as a rapid and simple method to assess free radical-scavenging 


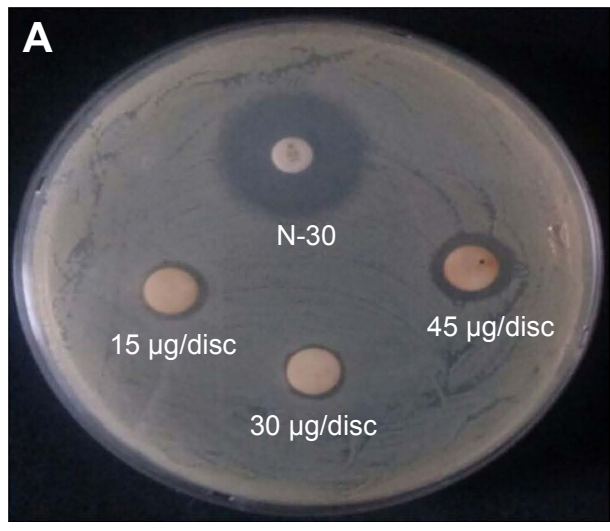

E. coli

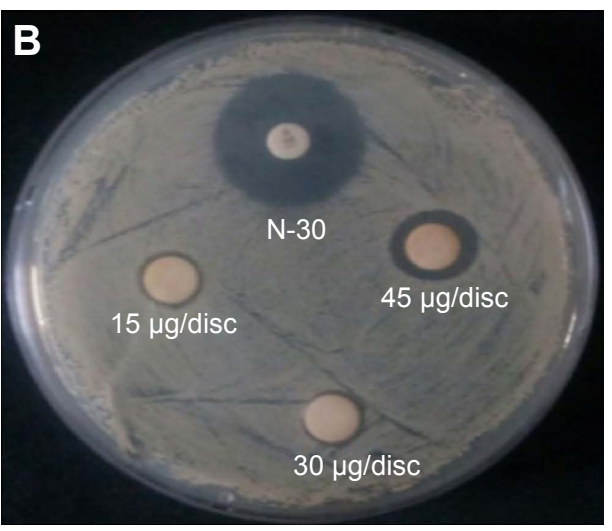

S. aureus

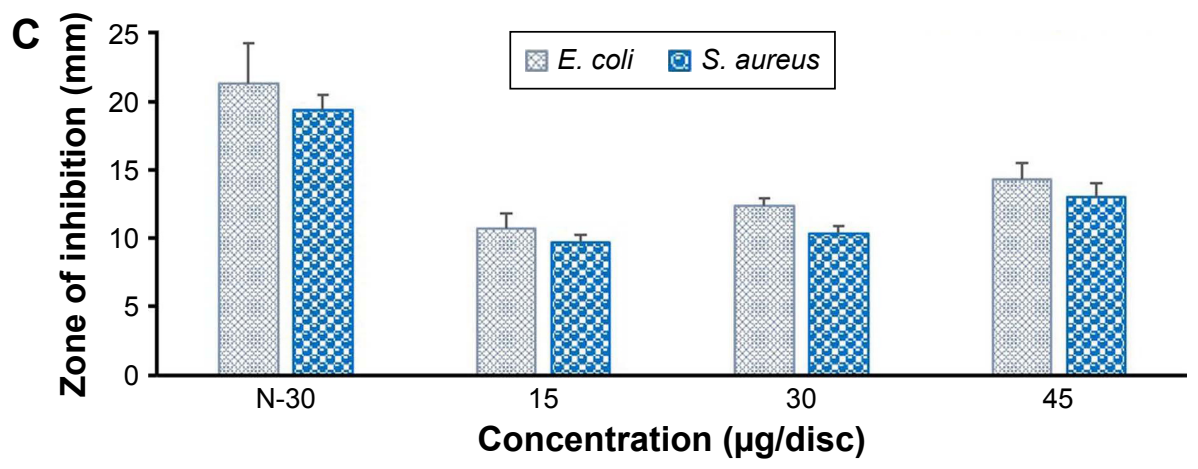

Figure 5 Antibacterial activity of BG-AgNps against Escherichia coli (A) and Staphylococcus aureus (B). Zone of inhibition of DH-AgNps and Neomycin as standard antibiotics as control against $E$. coli and $S$. aureus (C).

Abbreviations: BG, black ginseng; AgNps, silver nanoparticles; AuNps, gold nanoparticles.

ability. Free radical-scavenging ability of BG-AuNps and BG-AgNps was evaluated by monitoring the color change from purple to yellow at $517 \mathrm{~nm}$ by UV-Vis spectrophotometer. Stable free-radical molecules of DPPH were readily reduced by accepting hydrogen or electron from nanoparticles. The percentage inhibitions of BG root extract, BG-AuNps, and BG-AgNps are shown in Figure 6A. Inhibition was found to be slightly higher in BG-AgNps than in BG-AuNps. $\mathrm{The} \mathrm{IC}_{50}$ values, which indicate the minimum concentration of the samples to scavenge $50 \%$ of the free radicals, were ascertained graphically, and the results are shown in Figure 6B. The $\mathrm{IC}_{50}$ values of BG-capped AgNps $(2.05 \mu \mathrm{g} / \mathrm{mL})$ were less than the value obtained for BGcapped AuNps $(3 \mu \mathrm{g} / \mathrm{mL})$, since silver acts as a better oxidant than gold. ${ }^{34}$ However, $\mathrm{IC}_{50}$ value of $\mathrm{BG}$ root extract $(1.93 \mu \mathrm{g} /$ $\mathrm{mL}$ ) was less than the value of biosynthesized BG-AuNps and BG-AgNps. The DPPH radical inhibition of the precursor salts $\left(\mathrm{AgNO}_{3}\right.$ and $\left.\mathrm{HAuCl}_{4} \cdot 3 \mathrm{H}_{2} \mathrm{O}\right)$ showed low percentage

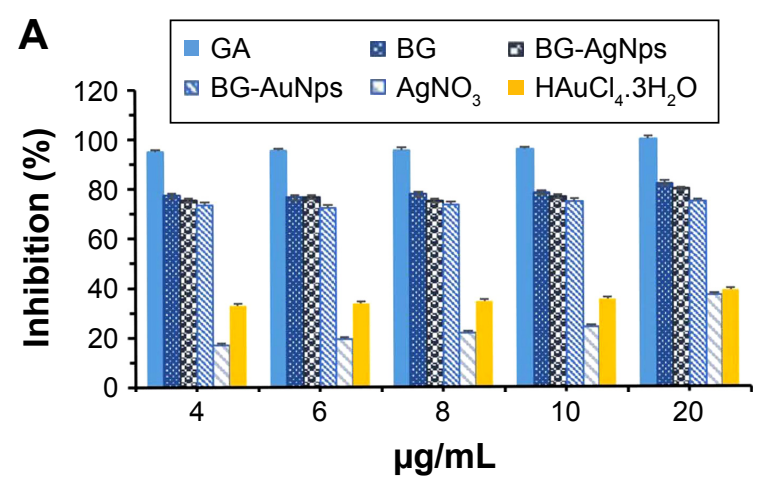

\section{B}

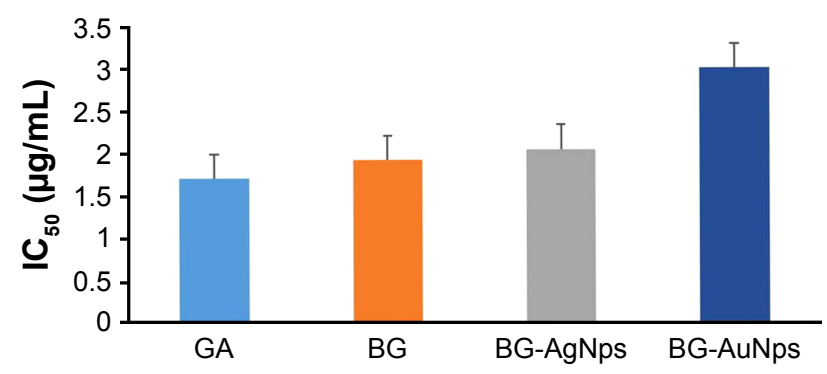

Figure 6 DPPH radical-scavenging activity of BG-AuNps and BG-AgNps using gallic acid as positive control $(\mathbf{A})$ and $I C_{50}$ comparison among gallic acid, BG, BG-AgNps, and BG-AuNps (B).

Abbreviations: DPPH, 2,2-diphenyl-I-picrylhydrazyl; BG, black ginseng; AuNps, gold nanoparticles; AgNps, silver nanoparticles; GA, gallic acid. 
A

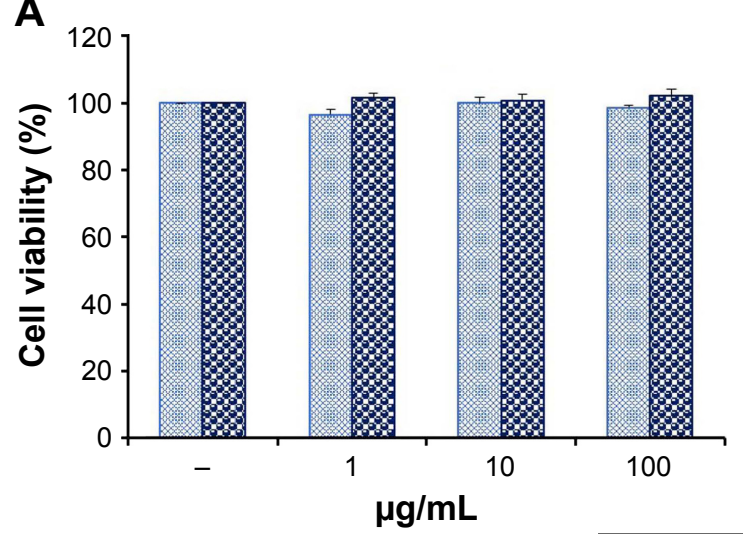

B

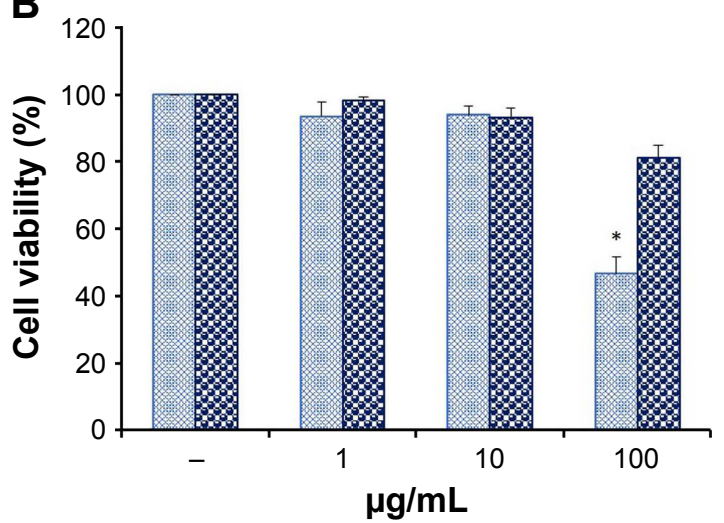

HaCaT $\mathbf{8}$ MCF-7

Figure 7 In vitro cytotoxicity of BG-AuNps (A) and BG-AgNps (B) in $\mathrm{HaCaT}$ and MCF-7 cell lines $(* P<0.05)$. Abbreviations: BG, black ginseng; AuNps, gold nanoparticles; AgNps, silver nanoparticles.

inhibition compared with their nanoparticle counterparts (data not shown). These results suggest that the increased free radical-scavenging activity of metal nanoparticles was attributed to the antioxidant activity of BG root extract. BGAuNps and BG-AgNps biosynthesized using BG root extract show promising prospect for the development of novel and biologically synthesized antioxidant agents.

\section{In vitro cytotoxicity of BG-AuNps and BG-AgNps in $\mathrm{HaCaT}$ and MCF-7 cells}

Different concentrations of each nanoparticle ranging from 1 to $100 \mu \mathrm{g} / \mathrm{mL}$ were adopted for MTT assay (Figure 7). BG-AuNps showed no cytotoxicity toward HaCaT and MCF-7 cells as seen in Figure 7A. This finding supports the biocompatibility of BG-AuNps in cancer cell lines. On the other hand, BG-AgNps did not exhibit significant cytotoxicity toward $\mathrm{HaCaT}$ and $\mathrm{MCF}-7$ cells at concentration lower than $10 \mu \mathrm{g} / \mathrm{mL}$ (Figure 7B). However, cell death was observed in $\mathrm{HaCaT}$ cells when exposed to high concentration $(100 \mu \mathrm{g} / \mathrm{mL})$.

Previous studies have reported the cytotoxic effect on MCF-7 cells of metallic nanoparticles. ${ }^{51,52}$ The absence of cytotoxicity suggests that they may be applied as costeffective and reliable mediators in cancer diagnostics and antibacterial agents in wound healing.

\section{Apoptotic activity of BG-AuNps and BG-AgNps in MCF-7 breast cancer cells}

Previous studies have reported the ability of metal-nanoparticle to induce apoptosis through the induction of ROS generation. ${ }^{53-55}$ Furthermore, the induction of cytotoxicity has been linked to the generation of ROS by AgNps in different cancer cell lines. ${ }^{37,54}$ In this study, the potential activity to induce oxidative cell damage and apoptosis by
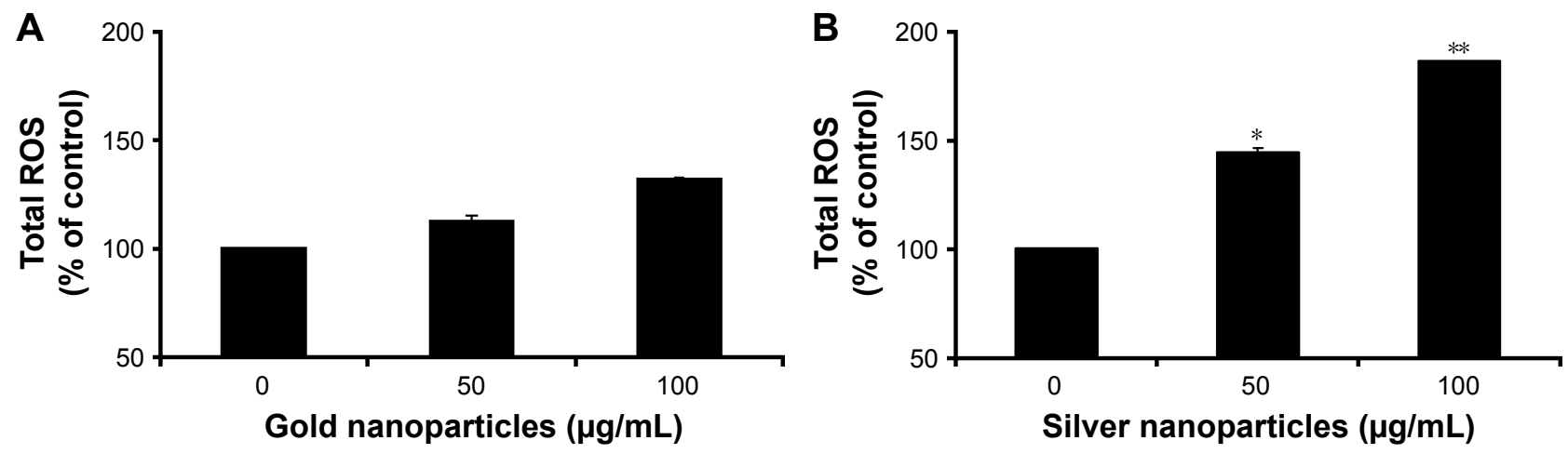

Figure 8 ROS generation of BG-AuNps (A) and BG-AgNps (B) in MCF-7 breast cancer cells. Note: ${ }^{*} P<0.05,{ }^{*} * P<0.01$.

Abbreviations: ROS, reactive oxygen species; BG, black ginseng; AuNps, gold nanoparticles; AgNps, silver nanoparticles. 
A

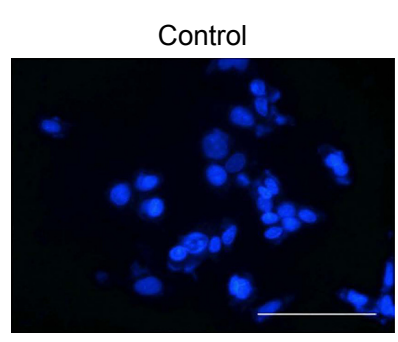

B

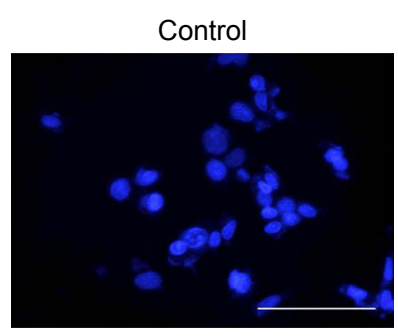

Gold

nanoparticles $(\mu \mathrm{g} / \mathrm{mL})$

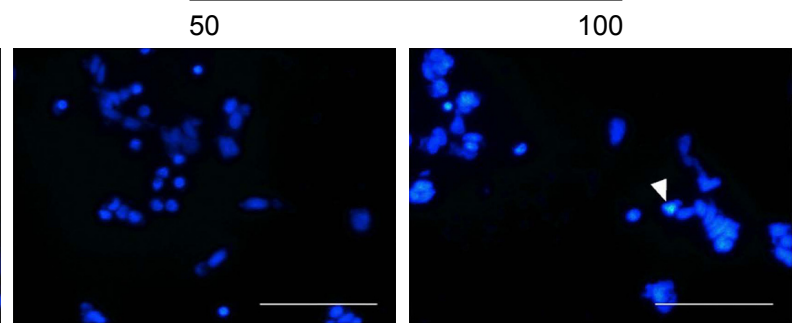

Silver

nanoparticles $(\mu \mathrm{g} / \mathrm{mL})$

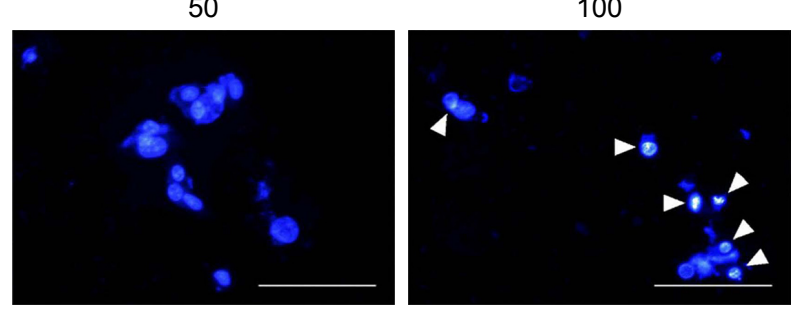

Figure 9 Cell apoptosis of BG-AuNps (A) and BG-AgNps (B) in MCF-7 breast cancer cells by Hoechst nuclear staining. Abbreviations: BG, black ginseng; AuNps, gold nanoparticles; AgNps, silver nanoparticles.

BG-AuNps and BG-AgNps through ROS generation and nuclear morphology alteration in $\mathrm{MCF}-7$ breast cancer cells was evaluated. It was found that BG-AuNps did not significantly enhance the production of ROS as well as the induction of morphological changes of the nucleus of MCF-7 cells (Figure 8A). On the other hand, BG-AgNps significantly increased ROS production at $100 \mu \mathrm{g} / \mathrm{mL}$ (Figure 8B). In addition, the apoptotic-positive cells, which exhibited nuclei fragmentation, were observed after treatment with $100 \mu \mathrm{g} / \mathrm{mL}$ of BG-AgNps (Figure 9). Previous studies have reported cell shrinkage, chromatin condensation, and nuclear fragmentation as potential signs of cell apoptosis. ${ }^{56,57}$ This result suggested the anticancer effect of BG-AgNps in MCF-7 breast cancer cell line. Further experiments are needed to elucidate the mechanism involved in this phenomenon.

\section{Conclusion}

In the present study, a green synthesis approach for BGAuNps and BG-AgNps is demonstrated for the first time using BG root extract. BG-AuNps and BG-AgNps were synthesized by a rapid, eco-friendly, and economical process in 3 minutes and 1 hour at $90^{\circ} \mathrm{C}$, respectively. Moreover, the biosynthesized BG-AgNps were spherical and monodisperse with narrow distribution, while BG-AuNps were icosahedralshaped and moderately polydisperse. The characterizations of BG-AuNps and BG-AgNps synthesized using WG, RG, and $\mathrm{BG}$ root extracts are displayed in Table 2 . The nanoparticles remained stable for 7 days in distilled water, sodium phosphate buffer ( $\mathrm{pH} 7.0$ ), Tris- $\mathrm{HCl}$ buffer ( $\mathrm{pH} 8.0$ ), and 5\% $\mathrm{BSA}$ solution at room temperature and $37^{\circ} \mathrm{C}$. The higher contents of ginsenoside and phytochemicals in $\mathrm{BG}$, which form a protective capping layer surrounding the nanoparticles,

Table 2 Synthesis of biological nanoparticles from white, red, and black Panax ginseng Meyer root extracts

\begin{tabular}{|c|c|c|c|c|c|c|}
\hline \multirow[t]{2}{*}{ Nanoparticles } & \multicolumn{2}{|l|}{ WG } & \multicolumn{2}{|l|}{$\mathbf{R G}$} & \multicolumn{2}{|l|}{ BG } \\
\hline & AgNps & AuNps & AgNps & AuNps & AgNps & AuNps \\
\hline Size range $(\mathrm{nm})$ & $10-30$ & $10-40$ & $10-30$ & $10-30$ & $5-30$ & $5-30$ \\
\hline Average metallic diameter $(\mathrm{nm})$ & 6.07 & 1.63 & - & - & 8 & 5 \\
\hline Hydrodynamic diameter (nm) & - & - & 83 & 183 & 213.20 & 273.40 \\
\hline PDI & - & - & 0.19 & 0.16 & 0.10 & 0.13 \\
\hline Shape & Spherical & Spherical & Spherical & Spherical & Spherical & lcosahedral \\
\hline Time (minutes) & 120 & 5 & 60 & 10 & 60 & 3 \\
\hline Temperature $\left({ }^{\circ} \mathrm{C}\right)$ & 80 & 80 & 80 & 80 & 90 & 90 \\
\hline
\end{tabular}

Abbreviations: WG, white ginseng; RG, red ginseng; BG, black ginseng; AgNps, silver nanoparticles; AuNps, gold nanoparticles; PDI, polydispersity index. 
played an important role in the bioreduction, stability, and enhanced free radical-scavenging activities of BG-AuNps and BG-AgNps. BG-AgNps also showed effective antibacterial activity against $E$. coli and $S$. aureus. In addition, BG-AuNps and BG-AgNps showed non-cytotoxicity in HaCaT and MCF-7 cells; the latter showed no significant cytotoxicity in $\mathrm{HaCaT}$ and $\mathrm{MCF}-7$ cells at concentrations less than $10 \mu \mathrm{g} / \mathrm{mL}$. Furthermore, BG-AuNps and BG-AgNps induced oxidative cell damage and apoptosis through ROS generation and nuclear morphology alteration in MCF-7 breast cancer cells, albeit in different capacities. Thus, the combinational antimicrobial, antioxidant, and cytotoxicity properties promote the utility of biogenic AuNps and AgNps in a wide range of biomedical applications.

\section{Acknowledgments}

This research was supported by the Korea Institute of Planning \& Evaluation for Technology in Food, Agriculture, Forestry \& Fisheries, Republic of Korea (KIPET NO: 316065031WT011[20161183]) and the Next-Generation BioGreen 21 Program (SSAC, grant\#: PJ0120342016), Rural Development Administration, Republic of Korea.

\section{Disclosure}

The authors report no conflicts of interest in this work.

\section{References}

1. Cui H, Feng Y, Ren W, Zeng T, Lv H, Pan Y. Strategies of large scale synthesis of monodisperse nanoparticles. Recent Pat Nanotechnol. 2009; 3(1):32-41.

2. Jain PK, Lee KS, El-Sayed IH, El-Sayed MA. Calculated absorption and scattering properties of gold nanoparticles of different size, shape, and composition: applications in biological imaging and biomedicine. J Phys Chem B. 2006;110(14):7238-7248.

3. Chen RJ, Bangsaruntip S, Drouvalakis KA, et al. Noncovalent functionalization of carbon nanotubes for highly specific electronic biosensors. Proc Natl Acad Sci U S A. 2003;100(9):4984-4989.

4. Ghodake G, Lee DS. Green synthesis of gold nanostructures using pear extract as effective reducing and coordinating agent. Korean $J$ Chem Eng. 2011;28(12):2329-2335.

5. Pradhan N, Pal A, Pal T. Silver nanoparticle catalyzed reduction of aromatic nitro compounds. Colloids Surf A Physicochem Eng Asp. 2002; 196(2-3):247-257.

6. Li Q, Mahendra S, Lyon DY, et al. Antimicrobial nanomaterials for water disinfection and microbial control: potential applications and implications. Water Res. 2008;42(18):4591-4602.

7. Jain D, Daima HK, Kachhwaha S, Kothari S. Synthesis of plantmediated silver nanoparticles using papaya fruit extract and evaluation of their anti microbial activities. Dig J Nanomater Biostruct. 2009;4(3): 557-563.

8. Veerasamy R, Xin TZ, Gunasagaran S, et al. Biosynthesis of silver nanoparticles using mangosteen leaf extract and evaluation of their antimicrobial activities. $J$ Saudi Chem Soc. 2011;15(2):113-120.

9. Raveendran P, Fu J, Wallen SL. Completely "green" synthesis and stabilization of metal nanoparticles. J Am Chem Soc. 2003;125(46): 13940-13941.
10. Mathiyalagan R, Kim YJ, Wang C, et al. Protopanaxadiol aglycone ginsenoside-polyethylene glycol conjugates: synthesis, physicochemical characterizations, and in vitro studies. Artif Cells Nanomed Biotechnol. Epub 2015 Nov 5.

11. Wu SD, Xia F, Lin XM, et al. Ginsenoside-Rd promotes neurite outgrowth of PC12 cells through MAPK/ERK- and PI3K/AKT-dependent pathways. Int J Mol Sci. 2016;17(2):177.

12. Xie J, Zhao D, Zhao L, et al. Characterization of a novel arabinose-tolerant $\alpha$-L-arabinofuranosidase with high ginsenoside $\mathrm{Rc}$ to ginsenoside $\mathrm{Rd}$ bioconversion productivity. J Appl Microbiol. 2016;120(3):647-660.

13. Choi KT. Botanical characteristics, pharmacological effects and medicinal components of Korean Panax ginseng CA Meyer. Acta Pharmacol Sin. 2008;29(9):1109-1118.

14. Mathiyalagan R, Subramaniyam S, Kim YJ, et al. Synthesis and pharmacokinetic characterization of a $\mathrm{pH}$-sensitive polyethylene glycol ginsenoside CK (PEG-CK) conjugate. Biosci Biotechnol Biochem. 2014;78(3):466-468.

15. Mathiyalagan R, Subramaniyam S, Kim YJ, Kim YC, Yang DC. Ginsenoside compound K-bearing glycol chitosan conjugates: synthesis, physicochemical characterization, and in vitro biological studies. Carbohydr Polym. 2014;112:359-366.

16. Jin Y, Kim YJ, Jeon JN, et al. Effect of white, red and black ginseng on physicochemical properties and ginsenosides. Plant Foods Hum Nutr. 2015;70(2):141-145.

17. Qi LW, Wang CZ, Yuan CS. American ginseng: potential structurefunction relationship in cancer chemoprevention. Biochem Pharmacol. 2010;80(7):947-954.

18. Ghosh P, Han G, De M, Kim CK, Rotello VM. Gold nanoparticles in delivery applications. Adv Drug Deliv Rev. 2008;60(11):1307-1315.

19. Naz F, Koul V, Srivastava A, Gupta YK, Dinda AK. Biokinetics of ultrafine gold nanoparticles (AuNPs) relating to redistribution and urinary excretion: a long-term in vivo study. J Drug Target. 2016; 24(8):720-729.

20. Sondi I, Salopek-Sondi B. Silver nanoparticles as antimicrobial agent: a case study on E. coli as a model for Gram-negative bacteria. J Colloid Interface Sci. 2004;275(1):177-182.

21. Morones JR, Elechiguerra JL, Camacho A, et al. The bactericidal effect of silver nanoparticles. Nanotechnology. 2005;16(10):2346-2353.

22. Wang C, Kim YJ, Singh P, Mathiyalagan R, Jin Y, Yang DC. Green synthesis of silver nanoparticles by Bacillus methylotrophicus, and their antimicrobial activity. Artif Cells Nanomed Biotechnol. 2016; 44(4):1127-1132.

23. El Khoury E, Abiad M, Kassaify ZG, Patra D. Green synthesis of curcumin conjugated nanosilver for the applications in nucleic acid sensing and anti-bacterial activity. Colloids Surf B Biointerfaces. 2015; 127:274-280.

24. Gupta B, Gautam D, Anjum S, Saxena S, Kapil A. Radiation synthesis of nanosilver nanohydrogels of poly(methacrylic acid). Radiat Phys Chem. 2013;92:54-60.

25. Anjum S, Gupta A, Sharma D, et al. Development of novel wound care systems based on nanosilver nanohydrogels of polymethacrylic acid with Aloe vera and curcumin. Mater Sci Eng C. 2016;64:157-166.

26. Singh P, Singh H, Kim YJ, Mathiyalagan R, Wang C, Yang DC. Extracellular synthesis of silver and gold nanoparticles by Sporosarcina koreensis DC4 and their biological applications. Enzyme Microb Technol. 2016;86:75-83.

27. Sun BS, Gu LJ, Fang ZM, et al. Simultaneous quantification of 19 ginsenosides in black ginseng developed from Panax ginseng by HPLCELSD. J Pharm Biomed Anal. 2009;50(1):15-22.

28. Singh P, Kim YJ, Wang C, Mathiyalagan R, El-Agamy Farh M, Yang DC. Biogenic silver and gold nanoparticles synthesized using red ginseng root extract, and their applications. Artif Cells Nanomed Biotechnol. 2016;44(3):811-816.

29. Singh P, Kim YJ, Wang C, Mathiyalagan R, Yang DC. The development of a green approach for the biosynthesis of silver and gold nanoparticles by using Panax ginseng root extract, and their biological applications. Artif Cells Nanomed Biotechnol. 2016;44(4):1150-1157. 
30. Singh P, Kim YJ, Yang DC. A strategic approach for rapid synthesis of gold and silver nanoparticles by Panax ginseng leaves. Artif Cells Nanomed Biotechnol. Epub 2015 Dec 24.

31. Omidi B, Hashemi SJ, Bayat M, Larijani K. Biosynthesis of silver nanoparticles by Lactobacillus fermentum. Bull Env Pharmacol Life Sci. 2014;3(12):186-192.

32. Leonard K, Ahmmad B, Okamura H, Kurawaki J. In situ green synthesis of biocompatible ginseng capped gold nanoparticles with remarkable stability. Colloids Surf B Biointerfaces. 2011;82(2):391-396.

33. Debnath R, Purkayastha DD, Hazra S, Ghosh NN, Bhattacharjee CR, Rout J. Biogenic synthesis of antioxidant, shape selective gold nanomaterials mediated by high altitude lichens. Mater Lett. 2016;169:58-61.

34. Ramamurthy CH, Padma M, Samadanam ID, et al. The extra cellular synthesis of gold and silver nanoparticles and their free radical scavenging and antibacterial properties. Colloids Surf B Biointerfaces. 2013;102:808-815.

35. Baltrušaitytė V, Venskutonis PR, Čeksterytė V. Radical scavenging activity of different floral origin honey and beebread phenolic extracts. Food Chem. 2007;101(2):502-514.

36. Ahn S, Siddiqi MH, Aceituno VC, et al. Ginsenoside Rg5: Rk1 attenuates TNF- $\alpha /$ IFN- $\gamma$-induced production of thymus- and activationregulated chemokine (TARC/CCL17) and LPS-induced NO production via downregulation of NF- $\mathrm{KB} / \mathrm{p} 38$ MAPK/STAT1 signaling in human keratinocytes and macrophages. In Vitro Cell Dev Biol Anim. 2016;52(3):287-295

37. Aceituno VC, Ahn S, Simu SY, Wang C, Mathiyalagan R, Yang DC. Silver nanoparticles from Dendropanax morbifera Léveille inhibit cell migration, induce apoptosis, and increase generation of reactive oxygen species in A549 lung cancer cells. In Vitro Cell Dev Biol Anim. Epub 2016 Jun 1.

38. Mock J, Barbic M, Smith D, Schultz D, Schultz S. Shape effects in plasmon resonance of individual colloidal silver nanoparticles. J Chem Phys. 2002;116(15):6755-6759.

39. Mohammed Fayaz A, Balaji K, Kalaichelvan PT, Venkatesan R. Fungal based synthesis of silver nanoparticles-an effect of temperature on the size of particles. Colloids Surf B Biointerfaces. 2009;74(1):123-126.

40. Tran HV, Dai Tran L, Ba CT, et al. Synthesis, characterization, antibacterial and antiproliferative activities of monodisperse chitosanbased silver nanoparticles. Colloids Surf A Physicochem Eng Asp. 2010;360(1):32-40.

41. Lee KS, El-Sayed MA. Gold and silver nanoparticles in sensing and imaging: sensitivity of plasmon response to size, shape, and metal composition. J Phys Chem B. 2006;110(39):19220-19225.

42. Bar H, Bhui DK, Sahoo GP, Sarkar P, De SP, Misra A. Green synthesis of silver nanoparticles using latex of Jatropha curcas. Colloids Surf A Physicochem Eng Asp. 2009;339(1-3):134-139.

43. Selvi JA, Rajendran S, Sri VG, Amalraj AJ, Narayanasamy B. Corrosion inhibition by beet root extract. Portugaliae Electrochim Acta. 2009;27(1):1-11.
44. Chien SW, Wang MC, Huang CC, Seshaiah K. Characterization of humic substances derived from swine manure-based compost and correlation of their characteristics with reactivities with heavy metals. J Agric Food Chem. 2007;55(12):4820-4827.

45. Marimuthu S, Rahuman AA, Rajakumar G, et al. Evaluation of green synthesized silver nanoparticles against parasites. Parasitol Res. 2011; 108(6):1541-1549.

46. Narayanan KB, Sakthivel N. Phytosynthesis of gold nanoparticles using leaf extract of Coleus amboinicus Lour. Mater Charact. 2010; 61(11):1232-1238.

47. Dar MA, Ingle A, Rai M. Enhanced antimicrobial activity of silver nanoparticles synthesized by Cryphonectria sp. evaluated singly and in combination with antibiotics. Nanomedicine. 2013;9(1):105-110.

48. Geethalakshmi R, Sarada DV. Gold and silver nanoparticles from Trianthema decandra: synthesis, characterization and antimicrobial properties. Int J Nanomedicine. 2012;7:5375-5384.

49. Prabhu S, Poulose EK. Silver nanoparticles: mechanism of antimicrobial action, synthesis, medical applications, and toxicity effects. Int Nano Lett. 2012;2(1):1-10.

50. Li WR, Xie XB, Shi QS, Zeng HY, Ou-Yang YS, Chen YB. Antibacterial activity and mechanism of silver nanoparticles on Escherichia coli. Appl Microbiol Biotechnol. 2010;85(4):1115-1122.

51. Vivek R, Thangam R, Muthuchelian K, Gunasekaran P, Kaveri K, Kannan S. Green biosynthesis of silver nanoparticles from Annona squamosa leaf extract and its in vitro cytotoxic effect on MCF-7 cells. Process Biochem. 2012;47(12):2405-2410.

52. Ahamed M, Akhtar MJ, Alhadlaq HA, Alshamsan A. Copper ferrite nanoparticle-induced cytotoxicity and oxidative stress in human breast cancer MCF-7 cells. Colloids Surf B Biointerfaces. 2016;142:46-54.

53. Park EJ, Yi J, Chung KH, Ryu DY, Choi J, Park K. Oxidative stress and apoptosis induced by titanium dioxide nanoparticles in cultured BEAS-2B cells. Toxicol Lett. 2008;180(3):222-229.

54. Piao MJ, Kang KA, Lee IK, et al. Silver nanoparticles induce oxidative cell damage in human liver cells through inhibition of reduced glutathione and induction of mitochondria-involved apoptosis. Toxicol Lett. 2011;201(1):92-100.

55. Sharma V, Anderson D, Dhawan A. Zinc oxide nanoparticles induce oxidative DNA damage and ROS-triggered mitochondria mediated apoptosis in human liver cells (HepG2). Apoptosis. 2012;17(8): $852-870$.

56. Wyllie AH, Kerr JF, Currie AR. Cell death: the significance of apoptosis. Int Rev Cytol. 1980;68:251-306.

57. Kerr JF, Wyllie AH, Currie AR. Apoptosis: a basic biological phenomenon with wide-ranging implications in tissue kinetics. Br J Cancer. 1972;26(4):239-257. 


\section{Supplementary material}

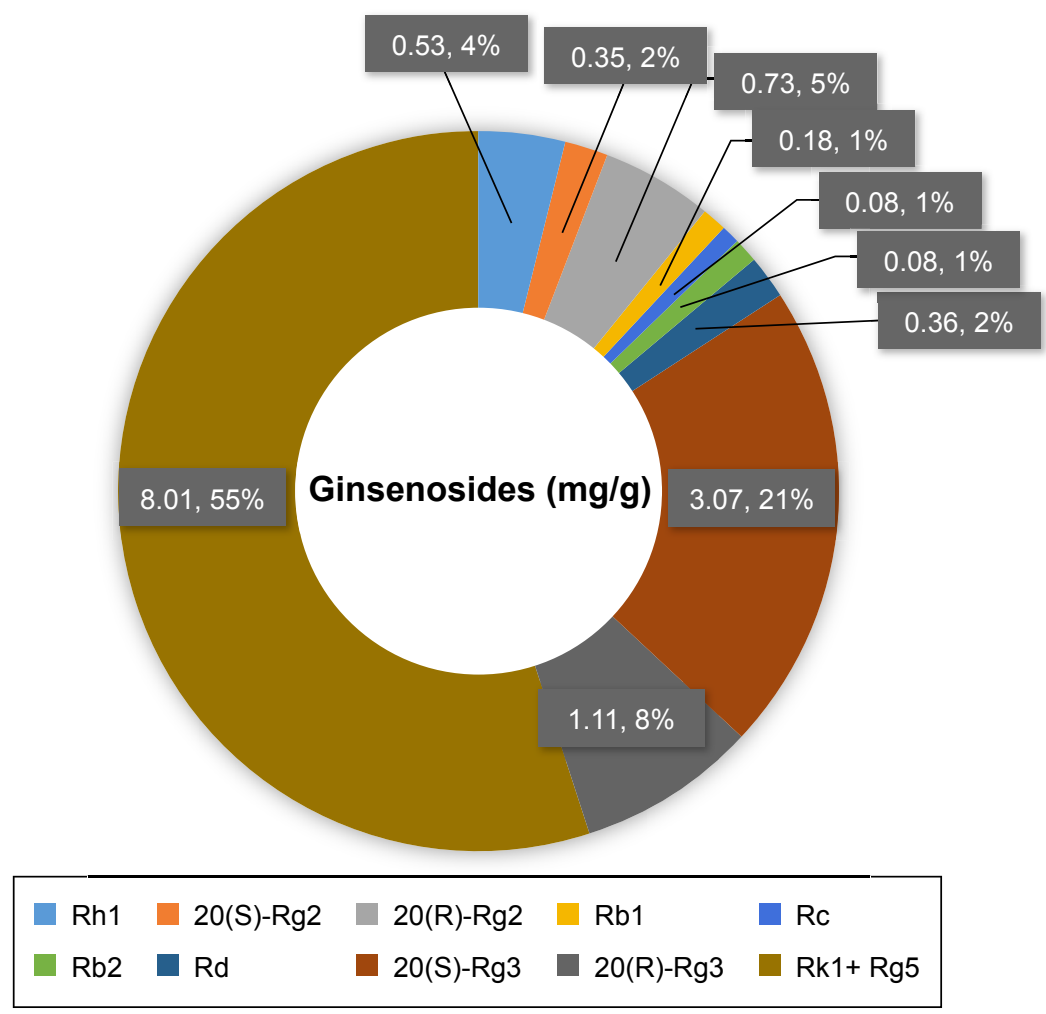

Figure SI The content of ginsenosides in black ginseng.

\section{Publish your work in this journal}

The International Journal of Nanomedicine is an international, peerreviewed journal focusing on the application of nanotechnology in diagnostics, therapeutics, and drug delivery systems throughout the biomedical field. This journal is indexed on PubMed Central, MedLine, CAS, SciSearch $®$, Current Contents ${ }^{\circledR} /$ Clinical Medicine,
Journal Citation Reports/Science Edition, EMBase, Scopus and the Elsevier Bibliographic databases. The manuscript management system is completely online and includes a very quick and fair peer-review system, which is all easy to use. Visit http://www.dovepress.com/ testimonials.php to read real quotes from published authors. 